\title{
Small world theory and the World Wide Web: linking small world properties and website centrality
}

\section{Davide Di Fatta*}

Department of Economical and Environmental Sciences, Business, Quantitative Technique,

University of Messina,

Messina, Italy

Email: difatta.davide@gmail.com

Email: ddifatta@unime.it

*Corresponding author

\section{Francesco Caputo}

Department of Computer Systems and Communications, Masaryk University,

Brno, Czech Republic

Email: fcaputo@mail.muni.cz

\section{Federica Evangelista}

Department of Economics and Law, University of Cassino and Southern Lazio, Cassino, Italy

Email: f.evangelista@unicas.it

\section{Gandolfo Dominici}

Department of Economics, Business and Statistics, University of Palermo,

Palermo, Italy

and

Business Systems Laboratory,

Avellino, Italy

Email: gandolfo.dominici@libero.it

\begin{abstract}
This qualitative paper aims to point out the incidence of small world characteristics in the World Wide Web. To this end, some theoretical implications of small world theory (SWT) are verified using information from focus groups and in-depth interviews administered to experts and users of the World Wide Web. The purpose of this study is to investigate whether it is possible to apply small world properties to online social networks while pointing out the key variables of website centrality in that context. Building on this, the paper traces possible contributions for better management of the World Wide Web in terms of the professional use of social media to facilitate information or product and service sharing. The results of the proposed
\end{abstract}


investigation highlight some pivotal aspects of small world properties on the web, as well as on website centrality. The findings are relevant for the application of social media marketing (SMM) and search engine optimisation (SEO).

Keywords: World Wide Web; small world theory; SWT; social media marketing; SMM; search engine optimisation; SEO.

Reference to this paper should be made as follows: Di Fatta, D., Caputo, F., Evangelista, F. and Dominici, G. (2016) 'Small world theory and the World Wide Web: linking small world properties and website centrality', Int. J. Markets and Business Systems, Vol. 2, No. 2, pp.126-140.

Biographical notes: Davide Di Fatta is a PhD student in Economics and Management at the University of Messina, Italy. He also collaborates with the SEAS Department at the Polytechnic School of the University of Palermo, Italy. He is a junior member referent of the Business System Laboratory. His main research fields are systems thinking, digital marketing, networks and social media

Francesco Caputo is Post-Doctoral Researcher and Lecturer in Service and System Thinking and in Knowledge Management at Department of Computer Systems and Communications, Masaryk University, Czech Republic. He is also Adjunct Professor of Knowledge Management at Department of Informatics, University of Bari, Italy. His main research interests include but are not limited to complexity, knowledge management, healthcare management, network theory, corporate communication, strategy, and systems thinking. He is Secretariat of the ASVSA, Association for research on Viable Systems (www.asvsa.org). He was also finalist at the 2012/2013 Emerald/EMRBI Business Research Award.

Federica Evangelista is a $\mathrm{PhD}$ student in Business Administration at the University of Cassino and Southern Lazio, Cassino, Italy.

Gandolfo Dominici is a tenured Associate Professor of Marketing at the Department SEAS of the University of Palermo, Italy. He is the Scientific Director and a co-Founder of the Business Systems Laboratory. He is a member of Directors Board of the World Organisation for Systems and Cybernetics (WOSC), Chair of the Special Integration Group 'Systems Applications in Business and Industry' for the International Society for the Systems Sciences (ISSS) and a member of the Council of Advisers of the Consorzio Universitario di Economia Industriale e Manageriale (CUEIM). $\mathrm{He}$ is the author of more than 70 published articles and books. His main research interests are marketing, e-marketing, new product development, systems thinking and organisational cybernetics.

\section{Introduction}

The opportunities offered by a global and interconnected economy in which there are no boundaries (Bauman, 2000; Saviano and Caputo, 2013; Dominici et al., 2016), and where it is possible to build directs links between companies and consumers, have been analysed from different viewpoints; various implications have been outlined both from 
theoretical and practical points of view (Berthon et al., 1996; Cockburn and Wilson, 1996; Eysenbach and Köhler, 2002; Barile et al., 2013; Del Giudice et al., 2016; Espejo and Dominici, 2016).

The existing literature on the topic of the web and social media marketing (SMM), underlines the relevance for companies (and other types of organisations) of using the opportunities offered by the web to build stronger relationships with consumers and the market (Ashley and Tuten, 2015; Hoffman and Fodor, 2010; Dominici, 2009). Despite this, most of the contributions offered by literature have focused their attention on the instruments used to maximise the effects of SMM (Evans, 2012; Tuten and Solomon, 2014), on the pathways to identifying better solutions with reference to the characteristics of companies and market (Mangold and Faulds, 2009), and on the implications that SMM and the web have on the organisations' plan and strategies (Berthon et al., 2012). Thanks to the capabilities of web users, it became possible for collaborators to support an organisation's actions, plans, and brands merely by speaking about them and creating interest in them (McLaren et al., 2002; Kretschmer and Aguillo 2004; Ebersbach et al., 2008).

In this context, among the different contributions to SMM and the web, an interesting advance in knowledge has been offered by managerial studies on the effect of marketing on online social networks (OSNs) (White et al., 2009). These contributions have shown that the influence of weak ties is similar to the influence of strong ties (Goldenberg et al., 2001; Henning-Thurau et al., 2004).

More specifically, analysing the influence of OSNs in social and market dynamics, it is easy to note that weak ties in OSNs have subverted more of the balances on which some recent economic systems are based (Ellison, 2007; Barile et al., 2015). According to Trusov et al. (2009), electronic word-of-mouth (e-WOM) referrals have substantially longer carryover effects than traditional marketing actions in influencing consumers' decisions and behaviours. This evidence has more relevant implications because organisations could obtain results similar to those of expensive SMM instruments and create strong ties simply by acting on weak ties and on users' collaborations and word-of-mouth.

In such a vein, the relevance of weak ties on the web needs to be better investigated in order to clarify the existing link between small world theory (SWT) and the web and to investigate the implications of SWT on the web. This paper this aims to investigate the following research questions:

\subsection{Can we apply small world properties on the World Wide Web?}

\subsubsection{What are the key variables of website centrality in the World Wide Web?}

Building on this, the paper aims to investigate possible contributions to better applying $\mathrm{SMM}$, in terms of the professional use of social media to facilitate information and product or service sharing (Tuten and Solomon, 2014), as well as search engine optimisation (SEO) as the science of driving web traffic to websites (Davis, 2006: Evans, 2007), the emergence of new business formats, and the survival of older ones (Hollensen, 2015).

The paper is structured as follows: in Section 2, we propose a conceptual and theoretical framework from which we derive four hypotheses to be tested with the qualitative information. In Section 3, we present the qualitative inquiry methodology. In 
Section 4, we present and discuss our findings and their match with the hypotheses from the preliminary literature review. The paper concludes with final remarks, implications, limitations of the research, and proposals for further research.

\section{Theoretical and conceptual framework}

\subsection{Small world theory}

SWT generalises and explores the common features of interconnected networks (Chatman, 1991; Watts, 1999). It is rooted in a graph theory built on Milgram's (1967) experiments. SWT outlines how, in a small world network, there are few degrees of separation between the elements of the net, but the intricate and richly aggregate structure of social groups is nonetheless maintained (Buchanan, 2003).

According to Okafor et al. (2007), it is possible in each small world network to identify two specific features: a high level of aggregation and a low degree of separation. The contributions to SWT clearly explain how it is possible to reconcile these two, apparently contradictory, features (Uzzi and Spiro, 2005). According to Aldrich and Kim (2007), each node of a small world network is oriented to build strong relationships with only a few others. However, this tendency does not exclude the possibility of nodes to build weak connections with other network elements (Granovetter, 1973). According to this, it is possible in a small world network to reach more connections through random weak ties (low degree of separation).

The probability that two randomly selected people (nodes) know each other was the subject of Milgram's (1967) experiments. In the final version of the experiment, Milgram chose random individuals from the US cities of Omaha, Nebraska, and Wichita, Kansas, as starting points, and Boston, Massachusetts, as the end-point of a chain of correspondence. He selected these cities because they were among the more socially and geographically distant cities in the USA.

In his experiment, Milgram used the so-called 'lost letter technique'. This involved a number of letters in envelope that displayed only the name of the recipient, with no address. He delivered the letters to some volunteers and explained that the letters should be delivered to the recipient. He did not indicate the addresses they were to be delivered to.

The letters that reached their destinations, almost all converged, in their last steps, to a small circle of friends of the recipient. The striking detail is that most letters reached the recipient in just six steps. For this reason, Milgram's experiment is often associated with the expression 'six degrees of separation', , although he never used it.

The major experimental result was that the average path length of chains was between 5.5 and 6 steps. Milgram concluded that, on average, about six steps separate American from each other; this finding is consistent with Guare's (1990) theory. Milgram concluded that the social world is far smaller than it is usually assumed to be.

Milgram's experiment did not avoid criticism. The main problem was the starting point of the letters. People were not randomly chosen, but were rather recruited through an advertisement that specifically sought people who considered themselves well connected to their friendship network (Kleinfeld, 2002).

Another problem with the experiment regards the attrition rate: if it is assumed that there is a constant level of non-response for each person in the chain, longer chains will 
be under-represented. It is more likely that they will encounter an unwilling participant. Considering these two objections together, it is possible to conclude that Milgram's experiment underestimates the average path length (Watts and Strogatz, 1998).

Despite criticising the experiment methodology, Watts and Strogatz agreed with Milgram's basic idea. They supported SWT showing the existence of small world networks in our daily lives, comparing it to the neural network of the worm Caenorhabditis elegans, the power grid of the western USA, and the collaboration graph of movie actors, which are said to show small world features (Watts and Strogatz, 1998).

The model proposed by Watts and Strogatz (1998) analytically defines the clustering coefficient and the degrees of separation for small world networks. Let $x_{i}$ be a point in the network and $x_{1}, x_{2}, \ldots, x_{j}, \ldots x_{n}$ be other points in the network. If each pair of different points $x_{i} \neq x_{j}$ is interconnected, then a state of maximum aggregation holds. In general, however, only a percentage of the direct neighbours of $x_{i}$ are interconnected. This fraction is a measure of the clustering coefficient: 0 represents no clustering and 1 represents maximum aggregation.

Watts and Strogatz proposed similar reflections with reference to degrees of separation. More specifically, they emphasised that, to measure the distance between two nodes of a network, it is need to measure the distance between the nodes of all possible pairs within the network. The average can then be defined and, in this ways, it is possible to calculate the exact number of degrees of separation of the network. This value is also the average number of steps necessary to connect two random points.

An alternative approach to measuring the distance between two random points in a network was proposed by Albert and Barabasi (2002). They indicated that a possible alternative solution requires the network's population to be investigated in the light of the social network perspective, in order to identify the average path length between any two nodes. They thus show that, considering an unweighted graph $G$ with a set of $n$ vertices $V$, let $d\left(v_{i}, v_{j}\right)$, where $\left(v_{i}, v_{j}\right) \in V$ denote the shortest distance between two nodes, assuming that $d\left(v_{i}, v_{j}\right)=0$ if $v_{i}$ cannot be reached from $v_{j}$. The average path length is:

$$
l_{G}=\frac{1}{n(n-1)} \sum_{i \neq j} d\left(v_{i}, v_{j}\right)
$$

As can be seen, SWT opens more relevant implications for every social and economic system based on the relationships between two or more actors. Among the different opportunities in understanding the social and economic dynamics illustrated by SWT, increasing attention is being paid to those related to the web as a new 'reality' in which rules and guidelines must still be written, and in which more challenges need to be faced by actors that aim for competitive advantages. In order to enrich the previous literature contributions to this topic, the next subsection presents a review of the relationships between the web and OSNs in the light of SWT.

\subsection{The World Wide Web and OSNs in the light of SWT}

The application of the principles and logic of SWT to the web and OSNs is a challenge to improving the opportunities and the positive effects related to the management of the web (Latora and Marchiori, 2001; Wang and Chen, 2003).

In this vein, building on the findings of Milgram's experiment, Dodds et al. (2003) attempted to investigate the validity of SWT on the web. Using an e-mail message, they 
requested 60,000 senders (the starting points) to deliver a package to 18 targets (arrivals) in 13 different countries. It emerged that, in some cases, the degree of separation was actually close to six, while in other cases the results failed to show small world properties.

A possible explanation for the conflicting findings of Dodds et al.'s experiment is related to the peculiarities of the internet. According to Watts et al. (2002), despite the immense size of the internet, only four connecting lines are active. Furthermore, some nodes - so-called hubs - are critical points that have more lines of connection than others.

Adamic and Huberman (2000) also showed that nodes and connections on the web are influenced by the power law (Newman, 2005), which define a functional relationship between two quantities such that, when one quantity (the independent variable) changes, the other quantity (dependent variable) changes faster than proportionally (Adamic et al., 2001). This evidence is underlined with previous studies of internet website topology which outlined how, whenever the number of connections doubles, the number of nodes with that number of connections decreases by a factor of five (Faloutsos et al., 1999).

Following the analysis of the conditions that influence the application of SWT to the web, it should be emphasised that the web is a scale-free network (Barabási, 2009). In other terms, it is a particular kind of network whose degree of distribution follows, at least asymptotically, the power law (Wang et al., 2006). According to this, if $P(k)$ is the percentage of nodes having $k$ connections and $\gamma$ is a parameter whose value typically lies in the range $2<\gamma<3$, then

$$
\lim _{n \rightarrow \infty} P(k) \cong k^{-\gamma}
$$

In a scale-free network, the most notable characteristic is the presence of vertices with a degree of centrality that greatly exceeds the average: the hubs. The scale-free property strongly correlates with the network's resilience (Cohen et al., 2000). In fact, hubs can be considered both a strength and a weakness of scale-free networks. If random failures occur, the likelihood that a hub would be affected is almost negligible. This is because the vast majority of nodes are those with a small degree of centrality. According to Freeman (1977), centrality can be defined as a function of the number of links incident on a node. This leads to a general condition for the critical fraction of nodes that need to be removed before the network disintegrates. For $\gamma \cong 3$, random attacks never disable the network. If a failure occurs in a hub, the network will generally not lose its connectedness because of the remaining hubs. Otherwise, if we intentionally choose a few major hubs and take them out of the network (direct attack), according to the so-called percolation theory, the network is turned into a set of rather isolated graphs (Callaway et al., 2000).

From what we have found in the literature, we can thus formulate the first three hypotheses that will later be tested:

$\mathrm{H}_{1}$ The web is an aristocratic scale-free network.

$\mathrm{H}_{2}$ The centrality of a website is a function of the number of back links leading to it.

$\mathrm{H}_{3}$ The centrality of a website is proportional to the centrality of the sites from which the back links derived.

Moving from studies on the application of SWT to the web, some researchers have also tried to investigate possible relations between SWT and OSNs (Gross and Acquisti, 2005; Mislove et al., 2007). There are many differences among OSNs, but also some common 
features, such as the construction of a public or semipublic profile within a bounded system, articulating a list of other users with whom there is a connection, and viewing and traversing the list of connections, and those made by others within the system (Boyd and Ellison, 2007).

The first studies that attempted to combine SWT and OSNs date back to 1996, when the game 'Six Degrees of Kevin Bacon' was invented by Fass, Turtle, and Ginelli, three students at Albright College in Pennsylvania. This game aimed to link any actor to Kevin Bacon through no more than six connections. The basic rule was that two actors were connected if they appeared together in a movie or a commercial. Fans of the game give other actors a 'Bacon Number' which is the minimum number of steps it takes to link them to the actor.

Kevin Bacon himself has a Bacon Number of zero. The Bacon number for actor $x$ is thus the number of steps in the shortest path that connects the actor $\mathrm{x}$ to Kevin Bacon. According to this, actors who have worked directly with Kevin Bacon have a Bacon Number of 1 . If the lowest Bacon number of any actor with whom $x$ has appeared in any movie is $n$, then that actor's Bacon number is $n+1$.

Fass et al. (1996) showed that this social network based on actors has the classic features of high aggregation (clustering coefficient) and low degree of separation (average path length). This is also confirmed by Watts and Strogats (1998), who outlined how, in a network with a size of 225,226 nodes, the average degree of separation is 61 , the average path length is 3.65 , and the clustering coefficient is 0.79 . From the above, we can formulate our fourth hypothesis:

$\mathrm{H}_{4}$ Social networking websites show small-world properties.

\section{Methodology}

In order to test our hypotheses and to point out the relations between SWT and the web, we have used a qualitative inquiry methodology based on focus groups and in-depth interviews. This methodology allowed us to develop a systematic and open-minded inquiry for understanding the perceptions of the interviewees and grasping their feelings (Burnard, 1991; Ang, 2014).

This inquiry was based on two steps: first, we carried out the focus group interviews, in which a group of people were conducted through a discussion (Merton, 1987; Frey and Fontana,1991; Morgan, 1997; Barbour and Kitzinger, 1998); then an in-depth interview on specific subjects was conducted in which the interviewee answered specific questions related to the topic of discussion of the focus group (Hollway and Jefferson, 1997; Boyce and Neale, 2006; Silverman, 2010; Easterby-Smith et al., 2012).

The choice of the focus group methodology was motivated by its appropriateness for online media and communications (Lunt and Livingstone, 1996) and generally for business and management studies (Ang, 2014; Milena et al., 2008).

Our focus group started in September 2015 in Messina, Italy. The group was of eight people, including a moderator, who did not directly participate to the discussion, but who moderated the group, took notes, and participated in the analysis of results. The other seven members were an e-commerce CEO, a social media manager, two web marketing consultants, an expert in SEO, and two ordinary internet users. ${ }^{2}$ As described by Morgan (1997), a focus group should include not only experts and professionals in the field, but 
also ordinary users. The questions were asked using the general principles of Krueger (1997): from the more general to the more specific (initial submissions, transition, key questions, final questions, and summary of responses), sorting application according to their importance in relation to the purpose of the discussion.

The 40 in-depth interviews were carried out in January 2016 in Palermo, Italy. The interviewees were again either experts in the field or regular non-professional internet users.

Having processing the data, we formalised four findings. Finally, in March 2016, these finding were presented to the respondents. In a completely anonymous way, they were asked to answer a questionnaire expressing, for each finding, the degree of approval on a five-point Likert scale in which ' 1 ' means 'strongly disagree' and ' 5 ' means 'strongly agree' (Likert, 1967; Albaum, 1997; Dawes, 2008).

\section{Findings and discussion}

Our hypotheses derived from the results of the qualitative studies were as follows:

$\mathrm{H}_{1}$ The web is an 'aristocratic' scale-free network.

According to the results of proposed study, H1 can be considered confirmed. More specifically, it emerges that the web follows the power law (Faloutsos et al., 1999) and that it is a scale-free network (Cohen et al., 2000; Wang et al., 2006). More specifically, the in-depth interview with an expert in Information and Communication Technologies (ICT) has been particularly enlightening to focus our attention on the 'aristocratic' (Buchanan, 2003) structure of this network. Citing the words of the interviewee \#7 "Let us suppose you need to participate in a challenge in the tug of war: the left team consists of eight vigorous boys and the right team consists of two skinny youngsters. Which team would you choose?" This finding is consistent with previous study of Albert et al. (2000) in which is underlined that internet is a particular case of small world network, characterised by hubs following the power law. Therefore, it can be defined as an 'aristocratic scale-free network'.

More specifically, Albert et al. (2000) studied the problem of scale-free networks from the point of view of a computer technician; their conclusions on the small-world structure of the web are quite similar to our findings. They analysed the structure of the web using an internet boot and found that the power law was applicable to 325,729 internet documents connected by 1,469,680 hypertext links. All these connections were characterised by the long-tail distribution described by Feldmann and Witt (1997). This example allows us to state again that a limited number of nodes have a high number of connections. On the other hand, a very large number of nodes have a limited number of connections.

Albert and his staff also calculated the so-called 'diameter of the web', (i.e., the typical distance between internet pages, determined by choosing two random pages and counting the number of clicks needed to move between them). They found this diameter to be about 19 clicks.

Moreover, in order to calculate this result, they applied a logarithmic dependence between the diameter of the web and the total number of documents in the network. This implies that, even assuming a $1000 \%$ increase of the size of the web, the diameter would 
increase from only 19 to 21 ; in other words, the diameter of a growing scale-free network can be considered almost steady (Albert et al., 2000).

$\mathrm{H}_{2}$ The centrality of a website is a function of the number of back links leading to it.

This hypothesis can be considered confirmed by the evidence of the study. This finding is consistent with the previous study of Bjorneborn and Ingwersen (2004), in which they affirmed that a back link represents a sort of 'favourable vote' for the receiving website from another webpage. More favourable votes thus correspond to greater centrality.

In order to explain this concept, we will use an analogy with a water network that emerged during in-depth interview \#17: the internet is not an egalitarian network; there are instead website hubs (e.g., search engines and online newspapers) that receive millions of hits per day. These hubs, in our analogy, are the large pipes that deliver a great deal of traffic with their links. Consider building two identical websites: the first receives an inbound link from the webpage of the most important national newspaper; the second website receives an inbound link from the website of a local school's magazine.

The amount of water (number of visitors) conveyed by the two pipes (incoming links) will obviously be different. The link from the highly connected hub brings a large volume of visitor traffic to the first website, while the link from the school magazine will generate only a few visits for the second website.

$\mathrm{H}_{3}$ The centrality of a website is proportional to the centrality of the sites from which the back links derived.

Hypothesis $\mathrm{H}_{3}$ can also be considered confirmed by the evidence of this study. During the in-depth interview, we found that an important factor is the anchor text of the back link. An anchor text is the descriptive label of a hyperlink that appears on a webpage (Aljaber et al., 2010). Search engine bots, such as spiders or crawlers, examine the anchor text to evaluate how relevant it is to the content on a webpage. Respondent \#18 pointed out that the anchor text (also known as link label, link text, or link title) is the visible and clickable text of the hyperlink. The words contained in the anchor text and their congruence with the content give more power to the link and to the website that is linked as a result.

Furthermore, anchor text and webpage content congruence is highly weighted in the rankings of a webpage with respect to any given keyword query by a search engine user.

$\mathrm{H}_{4}$ Social networking websites show small-world properties.

Finally, $\mathrm{H}_{4}$ can also be considered confirmed. More specifically, the results of the study show that respondents applied mental patterns similar to those found in a tug-of-war. In fact, we noted in the focus groups that many people registered on Facebook because many of their friends were already registered.

The web-marketing expert also noted that: "A page with a huge number of 'likes' and comments is much more attractive to a user than a page with few followers".

This finding was confirmed during in-depth interview \#3: the respondent, in choosing between Twitter and Google Plus, preferred Twitter because it had the highest number of subscribers. It is thus possible to affirm that $\mathrm{H}_{4}$ is also accepted and that 'Social networking websites show small-world properties'. This result is aligned with the first world-scale social network graph-distance computations by Ugander et al. (2011), who made three observations: 
1 the global structure of the graph determines that the social network is nearly fully connected, with $99.91 \%$ of individuals belonging to a single large connection

2 by studying the average local clustering coefficient and the degeneracy of the graph neighbourhoods, it is possible to show that, while the Facebook graph as a whole is clearly sparse, the graph neighbourhoods of users contain a surprisingly dense structure

3 there is a strong effect of age on friendship preferences, as well as a globally modular community structure driven by nationality, but there is no strong gender homophile.

Similarly, Backstrom et al. (2012) determined that, between all Facebook users (721 million users with 69 billion friendship links at the time the research was conducted), there is an average distance of 4.74 steps, corresponding to 3.74 intermediaries. Barnett (2011) suggested there are fewer than six degrees of separation that connect users within OSNs - probably between four and five.

A further favourable opinion came from studies carried out on Twitter: analysing more than 5.2 billion Twitter friendships and followers, Cheng (2010) found that the average distance between nodes is 4.67 steps.

Therefore, after visiting an average of 3.32 people within the friend network, Twitter users can expect to find one of their followers with a standard deviation of 1.25 friendship distances. In other words, this means there are many small circular connections on Twitter, just as in a classical small-world network.

Building on the results of the research, in order to verify its validity and agreement with the opinions and perspectives of the sample, the respondents were asked to evaluate their levels of agreement with the findings using a five-point Likert scale, on which 1 means 'strongly disagree' and 5 means 'strongly agree' (see Table 1).

Table 1 Result validation

\begin{tabular}{lccccc}
\hline Findings & 1 & 2 & 3 & 4 & 5 \\
\hline $\begin{array}{l}\text { The web is an aristocratic scale-free } \\
\text { network }\end{array}$ & $5 \%$ & $5 \%$ & $5 \%$ & $5 \%$ & $80 \%$ \\
$\begin{array}{l}\text { The centrality of a website is a function of } \\
\text { the number of back links. }\end{array}$ & $0 \%$ & $0 \%$ & $5 \%$ & $5 \%$ & $90 \%$ \\
$\begin{array}{l}\text { The centrality of a website is proportional } \\
\text { to the centrality of the sites from which the } \\
\text { back links derived. }\end{array}$ & $0 \%$ & $5 \%$ & $5 \%$ & $5 \%$ & $85 \%$ \\
$\begin{array}{l}\text { Social networking websites show small- } \\
\text { world properties }\end{array}$ & $0 \%$ & $5 \%$ & $5 \%$ & $15 \%$ & $75 \%$ \\
\hline Average & $1.25 \%$ & $3.75 \%$ & $5.00 \%$ & $7.50 \%$ & $82.50 \%$ \\
\hline
\end{tabular}

Adding up those who responded 'very agree' or 'agree', 90\% of respondents expressed a positive opinion. Only $5 \%$ overall disagree or strongly disagree with our formulation of the findings. These results support our analysis giving strength to the findings. 


\section{Final remarks, implications, and future lines of research}

The opportunities offered by the web represent an interesting challenge to both researchers and practitioners (Bhargava and Krishnan, 1998; Kaplan and Haenlein, 2010). The implications, rules, and risks are required to broaden traditional perspectives and to include variables and dimensions usually underestimated by traditional models and approaches.

In order to enrich earlier literature contributions on the management of the web, this paper proposes a quality study to determine whether it is possible to apply SWT to the web domain and what the key variables are in considering the definition of possible managerial models of centrality on the web.

In this line, the study aims to create a bridge between Milgram's SWT and the web. It thus provides a concrete approach for combining theoretical perspectives with the technical contributions offered by practitioners.

Reflections and empirical evidence show that small world network properties can be applied to the web. This finding permits more relevant implications with reference to a better management of tools offered by the web and OSNs.

The application of SWT proprieties to the web also broadens the perspective in the application of SMM, as a way to improve the opportunities of communication linked to the web and to better manage the relationships of companies with market (Hoffman and Fodor, 2010; Ashley and Tuten, 2015; Evangelista et al., 2016).

Other implications can be traced to the SEO field. The concept of centrality has a disruptive effect on the optimisation for search engines (such as Google, Bing, etc.). Considering that website centrality is determined by the number and power $\left(\mathrm{H}_{3}\right)$ of its back links $\left(\mathrm{H}_{2}\right)$, it is possible to state that website centrality depends on website network. Assuming that SEO allows the management of website networks (Evans, 2007), we agree with Baye et al. (2016) and consider SEO a relevant domain in defining future trends and dynamics for every type of company and organisation based on market relationships.

This paper thus traces a new possible pathway for further research that could deepen studies related to the web and so-called network orchestration, which is the process of assembling and developing an interorganisational network (Paquin and Howard-Grenville, 2013).

In these terms, the reflections and empirical results presented here cannot be considered exhaustive, but are only the first steps in a long research pathway aimed at better investigating the link between the web, SWT, and OSNs - also via empirical analysis of wider samples with different cultural backgrounds.

To face this challenge, a multidisciplinary and transdisciplinary effort is required, but the opportunities to identify better pathways to manage the complexity of the web deserve the engagement of both researchers and practitioners.

\section{Acknowledgements}

To conform with Italian regulations on academic publishing, even though the article is the joint work of all the authors, we attribute the contribution of each author as follows: Davide Di Fatta, Sections 2 and 3 Francesco Caputo: Section 4 Federica Evangelista, Section 5 and Gandolfo Dominici Section 1. 


\section{References}

Adamic, L.A. and Huberman, B.A. (2000) 'Power-law distribution of the World Wide Web', Science, Vol. 287, No. 5461, pp.2115-2115.

Adamic, L.A., Lukose, R.M., Puniyani, A.R. and Huberman, B.A. (2001) 'Search in power-law networks', Physical Review, Vol. 64, No. 4, p.046135.

Albaum, G. (1997) 'The Likert scale revisited: an alternate version', Journal of the Market Research Society, Vol. 39, No. 2, pp.331-332.

Albert, R. and Barabási, A.L. (2002) 'Statistical mechanics of complex networks', Reviews of Modern Physics, Vol. 74, No. 1, pp.47-62.

Albert, R., Jeong, H. and Barabási, A.L. (2000) 'Diameter of the World Wide Web', Nature, Vol. 401, No. 6749, pp.130-131.

Aldrich, H.E. and Kim, P.H. (2007) 'Small worlds, infinite possibilities? How social networks affect entrepreneurial team formation and search', Strategic Entrepreneurship Journal, Vol. 1, Nos. 1-2, pp.147-165.

Aljaber, B., Stokes, N., Bailey, J. and Pei, J. (2010) 'Document clustering of scientific texts using citation contexts', Information Retrieval, Vol. 13, No. 2, pp.101-131.

Ang, S.H. (2014) Research Design for Business \& Management, Sage, London.

Ashley, C. and Tuten, T. (2015) 'Creative strategies in social media marketing: an exploratory study of branded social content and consumer engagement', Psychology and Marketing, Vol. 32, No. 1, pp.15-27.

Backstrom, L., Boldi, P., Rosa, M., Ugander, J. and Vigna, S. (2012) 'Four degrees of separation', Web Science, 2012, Proceedings of the 4th Annual ACM Web Science Conference, pp.33-42.

Barabási, A.L. (2009) 'Scale-free networks: a decade and beyond', Science, Vol. 325, No. 5939, pp.412-432.

Barbour, R. and Kitzinger, J. (Eds.) (1998) Developing Focus Group Research: Politics, Theory and Practice, Sage, London.

Barile, S., Carrubbo, L., Iandolo, F. and Caputo, F. (2013) 'From 'EGO' to 'ECO' in B2B relationships', Journal of Business Market Management, Vol. 6, No. 4, pp.228-253.

Barile, S., Saviano, M. and Caputo, F. (2015) 'How are markets changing? The emergence of consumers market systems', 3rd International Symposium Advances in Business Management 'Towards Systemic Approach, University of Perugia, 21-23 January.

Barnett, E. (2011) Facebook Cuts Six Degrees of Separation to Four, Telegraph, 22 November [online] http://www.telegraph.co.uk/technology/facebook/8906693/Facebook-cuts-sixdegrees-of-separation-to-four.html, 228 (accessed May 2012).

Bauman, Z. (2000) Liquid Modernity, Polity Press, UK.

Baye, M.R., De los Santos, B. and Wildenbeest, M.R. (2016) 'Search engine optimization: what drives organic traffic to retail sites?', Journal of Economics and Management Strategy, Vol. 25, No. 1, pp.6-31.

Berthon, P., Pitt, L. and Watson, R.T. (1996) 'Marketing communication and the World Wide Web', Business Horizons, Vol. 39, No. 5, pp.24-32.

Berthon, P.R., Pitt, L.F., Plangger, K. and Shapiro, D. (2012) 'Marketing meets Web 2.0, social media, and creative consumers: implications for international marketing strategy', Business Horizons, Vol. 55, No. 3, pp.261-271.

Bhargava, H.K. and Krishnan, R. (1998) 'The World Wide Web: opportunities for operations research and management science', INFORMS Journal on Computing, Vol. 10, No. 4, pp.359-383.

Bjorneborn, L. and Ingwerse, P. (2004) 'Toward a basic framework for webometrics', Journal of the American Society for Information Science and Technology, Vol. 55, No. 14, pp.1216-1227. 
Boyce, C. and Neale, P. (2006) Conducting In-Depth Interviews: A Guide for Designing and Conducting In-Depth Interviews for Evaluation Input, pp.3-7, Pathfinder International, Watertown, MA.

Boyd, D.M. and Ellison, N.B. (2007) 'Social networks sites: definition, history, and scholarship', Journal of Computer-Mediated Communication, Vol. 13, No. 1, pp.210-230.

Buchanan, M. (2003) Nexus: Small Worlds and the Groundbreaking Theory of Networks, Norton and Co., New York.

Burnard, P. (1991) 'A method of analysing interview transcripts in qualitative research', Nurse Education Today, Vol. 11, No. 6, pp.461-466.

Callaway, D.S., Newman, M.E.J., Strogatz, S.H. and Watts, D.J. (2000) 'Network robustness and fragility: percolation on random graphs', Physical Review Letters, Vol. 85, No. 5468 [online] http://dx.doi.org/10.1103/PhysRevLett.85.5468 (accessed April 2016).

Chatman, E.A. (1991) 'Life in a small world: applicability of gratification theory to information-seeking behavior', Journal of the American Society for Information Science, Vol. 42, No. 6, p.438.

Cheng, A. (2010) Six Degrees of Separation: Twitter Style, Sysomos Inc., University of Toronto.

Cockburn, C. and Wilson, T.D. (1996) 'Business use of the World-Wide Web', International Journal of Information Management, Vol. 16, No. 2, pp.83-102.

Cohen, R., Erez, K., Ben-Avraham, D. and Havlin, S. (2000) 'Resilience of the internet to random breakdowns', Physical Review Letters, Vol. 85, No. 4628 [online] http://dx.doi.org/10.1103/ PhysRevLett.85.4626 (accessed April 2016).

Davis, H. (2006) Search Engine Optimization, O’Reilly Media, Inc., Austin.

Dawes, J.G. (2008) 'Do data characteristics change according to the number of scale points used? An experiment using 5 point, 7 point and 10 point scales', International Journal of Market Research, Vol. 51, No. 1, pp.1-20.

Del Giudice, M., Caputo, F. and Evangelista, F. (2016) 'How decision systems changing? The contribution of Social Media to the management decisional liquefaction', Journal of Decision Systems, http://dx.doi.org/10.1080/12460125.2016.1187546.

Dodds, P.S., Muhamad, R. and Watts, D.J. (2003) 'An experimental study of search in global social networks', Science, Vol. 8, No. 5634, pp.827-829.

Dominici, G. (2009) E-marketing. analisi dei cambiamenti dai modelli di business al mix operative, FrancoAngeli, Milan, Italy.

Dominici, G., Roblek, V. and Lombardi, R. (2016) 'A holistic approach to comprehending the complexity of the post-growth era: the emerging profile', in Erçetin, Ş.Ş. (Ed.): Chaos, Complexity and Leadership, pp.29-42, Springer.

Easterby-Smith, M., Thorpe, R. and Jackson, P.R. (2012) Management Research, Sage, London.

Ebersbach, A., Glaser, M., Heigl, R. and Warta, A. (2008) Wiki: Web Collaboration, Springer Science \& Business Media, New York.

Ellison, N.B. (2007) 'Social network sites: definition, history, and scholarship', Journal of Computer-Mediated Communication, Vol. 13, No. 1, pp.210-230.

Espejo, R. and Dominici, G. (2016) 'Cybernetics of value cocreation for product development', Systems Research and Behavioral Science, http://onlinelibrary.wiley.com/doi/10.1002/sres.2392/pdf.

Evangelista, F., Caputo, F., Russo, G. and Buhnova, B. (2016) 'Voluntary corporate disclosure in the era of social media', 4th International Symposium Advances in Business Management. 'Towards Systemic Approach', Mikolas Romeris University, Vilnius, Lituania, 24-26 August.

Evans, D. (2012) Social Media Marketing: An Hour a Day, John Wiley \& Sons, New York.

Evans, M.P. (2007) 'Analysing Google rankings through search engine optimization data', Internet Research, Vol. 17, No. 1, pp.21-37. 
Eysenbach, G. and Köhler, C. (2002) 'How do consumers search for and appraise health information on the World Wide Web? Qualitative study using focus groups, usability tests, and in-depth interviews', $B M J$, Vol. 324, No. 7337, pp.573-577.

Faloutsos, M., Faloutsos, P. and Faloutsos, C. (1999) 'On power-law relationship of the internet topology’, Computer Communication Review, Vol. 29, No. 4, pp.251-262.

Fass, C., Turtle, B. and Ginelli, M. (1996) Six Degrees of Kevin Bacon, Plume Penguin Group, New York.

Feldmann, A. and Whitt, W. (1997) 'Fitting mixtures of exponentials to long-tail distributions to analyze network performance models', INFOCOM'97: Sixteenth Annual Joint Conference of the IEEE Computer and Communications Societies: Driving the Information Revolution, Proceedings IEEE, Vol. 3, pp.1096-1104, April, IEEE.

Freeman, L. (1997) 'A set of measures of centrality based on betweeness', Sociometry, Vol. 40, No. 1, pp.35-41.

Frey, J.H. and Fontana, A. (1991) 'The group interview in social research', The Social Science Journal, Vol. 28, No. 2, pp.175-187.

Goldenberg, J., Libai, B. and Muller, E. (2001) 'Tale of the network: a complex systems look at the underlying process of word-of-mouth', Marketing Letters, Vol. 12, No. 3, pp.211-223.

Granovetter, M. (1973) 'The strength of weak ties', American Journal of Sociology, Vol. 78, pp.1360-1380.

Gross, R. and Acquisti, A. (2005) 'Information revelation and privacy in online social networks', Proceedings of the 2005 ACM Workshop on Privacy in the Electronic Society, November, pp.71-80, ACM.

Guare, J. (1990) Six Degrees of Separation: A Play, Vintage Book Random House LLC, New York.

Henning-Thurau, T., Gwinner, K.P., Walsh, G. and Gramler, D.D. (2004) 'Electronic word-of-mouth via consumer opinion platforms: what motivates consumers to articulate themselves on the internet?', Journal of Interactive Marketing, Vol. 18, No. 1, pp.38-52.

Hoffman, D.L. and Fodor, M. (2010) 'Can you measure the ROI of your social media marketing', MIT Sloan Management Review, Vol. 52, No. 1, pp.41-49.

Hollensen, S. (2015) Marketing Management: A Relationship Approach, Pearson Education, New York.

Hollway, W. and Jefferson, T. (1997) 'Eliciting narrative through the in-depth interview', Qualitative Inquiry, Vol. 3, No. 1, pp.53-70.

Kaplan, A.M. and Haenlein, M. (2010) 'Users of the world, unite! The challenges and opportunities of social media', Business Horizons, Vol. 53, No. 1, pp.59-68.

Kleinfeld, J. (2002) 'Six degrees: urban myth?', Psychology Today, Vol. 35, No. 2, pp.20-34.

Kretschmer, H. and Aguillo, I. (2004) 'Visibility of collaboration on the web', Scientometrics, Vol. 61, No. 3, pp.405-426.

Krueger, R.A. (1997) Analyzing and Reporting Focus Group Results, Sage, London.

Latora, V. and Marchiori, M. (2001) 'Efficient behavior of small-world networks', Physical Review Letters, Vol. 87, No. 19, pp.198-217.

Likert, R. (1967) 'The method of constructing and attitude scale', Methods and Techniques in Business Research, New York.

Lunt, P. and Livingstone, S. (1996) 'Rethinking the focus group in media and communications research', Journal of Communication, Vol. 46, No. 2, pp.79-98.

Mangold, W.G. and Faulds, D.J. (2009) 'Social media: the new hybrid element of the promotion mix’, Business Horizons, Vol. 52, No. 4, pp.357-365.

McLaren, T., Head, M. and Yuan, Y. (2002) 'Supply chain collaboration alternatives: understanding the expected costs and benefits', Internet Research, Vol. 12, No. 4, pp.348-364. 
Merton, R.K. (1987) 'The focussed interview and focus groups: continuities and discontinuities', The Public Opinion Quarterly, Vol. 51, No. 4, pp.550-566.

Milena, Z.R., Dainora, G. and Alin, S. (2008) 'Qualitative research methods: a comparison between focus-group and in-depth interview', Annals of the University of Oradea, Economic Science Series, Vol. 17, No. 4, pp.1279-1283.

Milgram, S. (1967) ‘The small-world problem', Psychology Today, Vol. 2, No. 1, pp.60-67.

Mislove, A., Marcon, M., Gummadi, K.P., Druschel, P. and Bhattacharjee, B. (2007) 'Measurement and analysis of online social networks', Proceedings of the 7th ACM SIGCOMM Conference on Internet Measurement, October, pp.29-42, ACM.

Morgan, D.L. (1997) The Focus Group Guidebook, Vol. 1, Sage, London.

Newman, M.E.J. (2005) 'Power laws, Pareto distributions and Zipf's law', Contemporary Physics, Vol. 46, No. 5, pp.323-351.

Okafor, A., Pardalos, P. and Ragle, M. (2007) 'Data mining via entropy and graph clustering', Data Mining in Biomedicine, Springer, New York, USA.

Paquin, R.L. and Howard-Grenville, J. (2013) 'Blind dates and arranged marriages: longitudinal process of network orchestration', Organization Studies, Vol. 34, No. 1, pp.1623-1653.

Saviano, M. and Caputo, F. (2013) 'Managerial choices between systems, knowledge and viability', in Barile, S. (Ed.): Contributions to Theoretical and Practical Advances in Management: A Viable Systems Approach (VSA), pp.219-242, ARACNE Editrice S.r.1., Roma.

Silverman, D. (Ed.) (2010) Qualitative Research, Sage, London.

Trusov, M., Bucklin, R.E. and Pauwels, K. (2009) 'Effects of word of mouth versus traditional marketing: findings from an internet social networking site', Journal of Marketing, Vol. 73, No. 5, pp.90-102.

Tuten, T.L. and Solomon, M.R. (2014) Social Media Marketing, Sage, London.

Ugander, J., Karrer, B., Backstrom, L. and Marlow, C. (2011) The Anatomy of the Facebook Social Graph, Cornell University Library, London.

Uzzi, B. and Spiro, J. (2005) 'Collaboration and creativity: the small world problem', American Journal of Sociology, Vol. 111, No. 2, pp.447-504.

Wang, W.X., Wang, B.H., Yin, C.Y., Xie, Y.B. and Zhou, T. (2006) 'Traffic dynamics based on local routing protocol on a scale-free network', Physical Review, Vol. 73, No. 2, pp.96-111.

Wang, X.F. and Chen, G. (2003) 'Complex networks: small-world, scale-free and beyond', Circuits and Systems Magazine, Vol. 3, No. 1, pp.6-20, IEEE.

Watts, D.J. (1999) 'Networks, dynamics, and the small-world phenomenon 1', American Journal of Sociology, Vol. 105, No. 2, pp.493-527.

Watts, D.J. and Strogatz, S.H. (1998) 'Collective dynamics of small-world networks', Nature, Vol. 393, No. 6684, pp.440-442.

White, C., Plotnick, L., Kushma, J., Hiltz, S.R. and Turoff, M. (2009) 'An online social network for emergency management', International Journal of Emergency Management, Vol. 6, Nos. 3-4, pp.369-382.

\section{Notes}

1 The expression 'six degree of separations' is attributed to Guare (1990, p.28), who claimed that "On this planet only six individuals separate me from any other individual, whether it be the President of the United States or a gondolier in Venice".

2 The concept of an 'ordinary internet user' refers here to a person who uses the internet at least once a day. 